\title{
6 Wozu wird Gewalt ausgeübt? Oder die Frage nach Zielen, Absichten, Zwecken und möglichen Motiven
}

In unserer Welt mit ihren „flüchtigen Glücksverheißungen“ (Strasser 2001), ihrem ständig sich beschleunigenden Wandel, ihrer ungerechten Verteilung der Lebenschancen, ihren Globalisierungszwängen und wachsenden sozialen, technischen und ökologischen Risiken, ist es schwer, Jugendlichen deutlich zu machen, wie ein für sie erfülltes, glückliches und zufrieden stellendes Leben aussehen könnte.

Die grenzenlose „Gier des Habens“ wird ihnen täglich von Werbung, aber auch aktuellen Vorbildern in Wirtschaft und Politik vorgelebt. Sie haben nicht das Gefühl, aktiv an der Gestaltung des eigenen Lebens beteiligt zu sein. Umso mehr entwickeln sie die Vorstellung, das Recht zu haben, sich das nehmen zu können, von dem sie meinen, dass es ihnen eigentlich zusteht. Sie lehnen deshalb weitere Hilfen ab und wollen auch nicht zu einem „Funktionselement des Marktes“ (Strasser 2001) werden. Dass Jugendliche letztendlich mit den ihnen zur Verfügung stehenden Mitteln dagegen revoltieren, bleibt nicht aus. Gewaltaktionen sind für sie „Instrumente“, um ihre Wünsche zu erreichen. Erfahrene Ohnmacht provoziert ihre Gewaltbereitschaft, deren Gewaltsamkeit oft irrationale Züge annimmt, wenn sie zu „Ersatzhandlungen“ führt oder auf „Ersatzobjekte“ umorientiert wird (Arendt 1970).

Nach Meier (2011) erleben Jugendliche immer häufiger „Präzedenzfälle“, wie einer im Falle der Tötung von Osama Bin Laden durch die „Seals“ der US-Armee 
6 Wozu wird Gewalt ausgeübt?

Oder die Frage nach Zielen, Absichten, Zwecken und möglichen Motiven

in Pakistan geschaffen wurde. Dadurch wird die bisherige zivilisatorische Rechtsentwicklung seit den Nürnberger Prozessen „durchlöchert“, und es wird auch das Rechtsstaatsprinzip „atavistischen Revanchegefühlen“ vorschnell geopfert. Damit sei „die Rache wieder zurückgekehrt“ und „ihr gewaltverliebter Schatten, die unheimliche Freude an der Tötung" (Meier 2011).

Der Erfahrungshintergrund und die Motivlage der jugendlichen Täter sind nach Robertz und Wickenhäuser (2007) derart „selbstbezüglich“ und von der Lebenswelt der sonstigen Bevölkerung „abgekoppelt und so monströs“, dass es Außenstehenden schwerfällt, sie nachzuvollziehen.

Ch. Seung-Hui, Blackburg, tötete 32 und verletzte 29 Personen, bevor er sich selbst tötete. In einem „Video-Manifest“ äußerte er: „Ihr habt mich in die Ecke gedrängt. Jetzt müsst ihr damit leben, dass Blut an Euren Händen klebt“.

Bei 57,1\% der Täter drohte eine Nichtversetzung oder Schulausschluss. 42,9\% verloren nahestehende Personen durch Tod. Andere Motive sind Zurückweisungen durch Mädchen und Mobbingerfahrungen (Hoffmann et al. 20o9; Bannenberg 2010b, du Bois 2010; Spröber und Fegert 2010).

Bei School Shootings wurden Schulen bewusst als Ort der Tötungen ausgesucht. Täter waren stets Schüler oder ehemalige Schüler dieser Institutionen. Dabei waren entweder mehrere Schüler oder Lehrer Ziel der Tötungsabsicht. Einzelne Opfer wurden von den Tätern auch wegen ihrer Funktion an einer Schule ausgesucht (Hoffmann und Wondrak 2007).

Menninger beschrieb schon 1938 als allen selbstmörderischen und mörderischen Handlungen gemeinsame Fantasie den dreifachen Wunsch der Täter, andere und sich selbst zu töten oder getötet zu werden. Den Tätern geht es auch um eine größtmögliche Medienaufmerksamkeit. Sie planen keinen stillen Massenmord, sondern eine „dramatische Inszenierung einer Realtragödie“ für Opfer und Täter.

Canetti (zitiert nach Wuketits 2010) schrieb:

„Man wird die Vermutung nicht los, dass hinter jeder Paranoia wie hinter jeder Macht dieselbe tiefere Tendenz und der Wunsch stecken, die anderen aus dem Weg zu räumen, damit man der einzige ist."

Bannenberg (2010a, b) untersuchte aus kriminalpsychologischer Sicht und mittels einer „psychologischen Autopsie“ fünfzehn Amokfälle mit tödlichem Ausgang. Er kommt zu dem Ergebnis, dass ihr Motiv „irrationaler Hass“ gewesen ist und fast alle Täter Verlusterfahrungen wie Status-Verlust, Verlust einer Liebesbeziehung, Verlust der körperlichen Unversehrtheit durch eine Krankheit hatten. Stabilisierende Faktoren waren bei ihnen weggebrochen. 


\section{Fallvignette}

Georg R., der Schulamokläufer aus Ansbach, äußerte zu seinen Motiven, dass er sich seit seiner Kindheit ausgegrenzt und missachtet gefühlt habe. Amokläufe hätten ihn fasziniert, weil er darin „einen klaren, geraden Weg“ gesehen habe. Er räumte in seinem Gerichtsprozess ein, möglichst viele Menschen töten zu wollen. In der Urteilsbegründung durch das Gericht wurde „sein Hass auf andere " benannt, weil er sich von ihnen ungerecht behandelt fühlte, „Hass auf die Schule", weil sie inn kaputt gemacht habe und er deshalb eine "Sehnsucht nach weltweiter Anerkennung durch eine spektakuläre Tat" entwickelt habe.

Insgesamt lässt sich bei der Analyse der unterschiedlichsten Motivlagen ein multikausales Zusammenspiel mehrerer Einzelfaktoren feststellen, ohne dass ein eindeutiges „Täter-Profil“ ersichtlich wird:

\section{Unterschiedliche Motivlagen für die Ausübung von Gewalttaten}

- gemobbt werden in der Schule,

- unangemessener Leistungsdruck,

- Entwicklung von Zukunftsängsten,

- Kommunikationsarmut,

- mangelnde Integration im Elternhaus und im sozialen Umfeld,

- soziale Vereinsamung und Isolation,

- Versager- und Einzelgängerschicksale,

- Konflikte mit nahestehenden Personen,

- Kompensation von erfahrenen Kränkungen oder Minderwertigkeitsgefühlen durch extreme Handlungen,

- Nachahmung ähnlicher vorangegangener Taten,

- geplantes Erregen der medialen Aufmerksamkeit. 